DOI: https://doi.org/10.47405/mjssh.v6i3.712

\begin{tabular}{|c|c|}
\hline 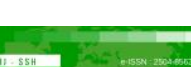 & Malaysian Journal of Social Sciences and Humanities (MJSSH) \\
\hline Malaysian Journal of & Volume 6, Issue 3, March 2021 \\
\hline (MJ-ssH) & e-ISSN : 2504-8562 \\
\hline & $\begin{array}{l}\text { Journal home page: } \\
\text { www.msocialsciences.com }\end{array}$ \\
\hline
\end{tabular}

\title{
Analisis Aras Kognitif Bagi Soalan dalam Buku Teks Matematik Tahun 4 KSSR Semakan
}

\author{
Azriana Abdul Azis' ${ }^{1}$, Roslinda Rosli ${ }^{1}$ \\ ${ }^{1}$ Fakulti Pendidikan, Universiti Kebangsaan Malaysia (UKM) \\ Correspondence: Azriana Abdul Azis (azrianaazis92@gmail.com)
}

\begin{abstract}
Abstrak
Buku teks merupakan indikator terbaik dalam mengukur dan melatih kemahiran berfikir aras tinggi (KBAT) khususnya dalam mata pelajaran Matematik kerana ia menepati sukatan kurikulum yang seragam di semua sekolah. Kajian ini dijalankan bertujuan untuk menganalisis secara empirikal dan sistematik berkaitan aras kognitif yang digunakan dalam buku teks Matematik Tahun 4 KSSR Semakan 2017. Sebanyak 921 soalan di dalam buku teks telah dikelaskan mengikut kod aras kognitif yang ditentukan oleh Model Kod Analisis Aras Kognitif Soalan sebelum diproses dan dianalisis secara deskriptif statistik menggunakan program SPSS Version 23. Dapatan kajian mendapati bahawa buku teks Matematik Tahun 4 KSSR Semakan memiliki aras kognitif soalan yang sederhana dengan bilangan soalan yang dominan pada Tahap Inferensi. Elemen KBAT yang terlibat pula lebih berfokus kepada kemahiran mengaplikasikan dan menganalisis. Dapatan ini menunjukkan bahawa aras soalan dalam buku teks Matematik Tahun 4 KSSR Semakan 2017 adalah lebih tinggi berbanding aras soalan dalam buku teks Matematik KSSR 2011. Penambahbaikan ini bersesuaian dalam menyediakan murid dengan kemahiran berfikir yang selari dengan ujian TIMSS.
\end{abstract}

Kata kunci: buku teks, matematik, aras kognitif soalan, KSSR semakan, kemahiran berfikir aras tinggi

\section{Cognitif Level Analysis for Question in Revised KSSR Standard 4 Mathematics}

\begin{abstract}
Textbook is the best indicator for evaluating and training of Higher Order Thinking Skills (HOTS), especially in Mathematics subject as it complements the similar curricular syllabus in all school. This research was conducted to analyse empirically and systematically of the cognitive level in the Revised KSSR Standard 4 Mathematics Textbook version 2017. A total of 921 questions in the textbook had been classified according to the cognitive level code that was determined from Kod Analisis Aras Kognitif Soalan Model before being processed and analysed by descriptive statistics using SPSS Version 23. The Revised KSSR Standard 4 Mathematics Textbook was found out to comprise of intermediate level of cognitive questions with a dominant number of questions at the Inference Level. The HOTS elements that were involved are more focused on application and analysis skills. This research outcome shows that the level of questions in the Revised KSSR Standard 4 Mathematics Textbook version 2017 is higher than the level of questions in KSSR Mathematic Textbook version 2011. This improvement is seen as appropriate in order to equip the students with thinking skills corresponding to the TIMSS exam.
\end{abstract}


Keywords: textbook, mathematics, cognitive level of questions, KSSR revision, high order thinking skills.

\section{Pengenalan}

Matematik merupakan salah satu cabang ilmu Sains yang digunakan secara meluas dalam pelbagai bidang. Ia banyak diaplikasikan khususnya dalam bidang sains sosial, sains kemanusiaan, politik, ekonomi, perniagaan dan pembelajaran komputer. Oleh itu, manusia memerlukan kemahiran dalam pengurusan, kehidupan dan transaksi harian. Menurut Sabah et al. (2014), kemahiran yang dipelajari dalam kelas Matematik membantu pelajar dalam kehidupan seharian mereka di peringkat seterusnya. Maka tidak hairanlah jika kurikulum yang menekankan pembangunan aspek kemahiran saintifik dan teknikal dalam bidang Matematik lebih memberi impak yang besar terhadap pembangunan dan kemajuan negara. Hal ini telah terbukti di negara-negara maju, apabila rakyatnya memiliki kemahiran matematik dan analitik yang baik, negara tersebut mampu melahirkan lebih ramai saintis dan individu yang profesional dalam pelbagai bidang teknikal.

Selain itu, kemahiran Matematik mampu membantu pelajar dalam membuat keputusan melalui kemahiran berfikir secara rasional yang terbina semasa menyelesaikan sesuatu masalah. Hal ini menyumbang kepada kemahiran penyelesaian masalah harian dalam mencapai hasil yang lebih logik dan bernas. Melalui pemikiran analitik, pelajar menggunakan kemahiran kognitif mereka dalam membuat penaakulan berdasarkan formula logik dan data yang benar. Hal ini secara langsung memupuk kemahiran mengkaji dan meneroka yang membolehkan pelajar memahami dunia di sekeliling mereka melalui pemahaman berdasarkan pembuktian bukan emosi semata-mata. Justeru itu, matlamat utama dalam pembelajaran matematik ialah menyediakan individu menghadapi kehidupan di masa hadapan. Tambahan lagi, pendidikan matematik juga menyediakan pelajar dalam meneruskan kemahiran matematik dan subjek lain semasa di sekolah juga setelah tamat alam persekolahan. Fokus utama yang harus ditekankan ialah fungsi kurikulum sebagai input yang memainkan peranan penting dalam reformasi dan perkembangan proses pendidikan sejajar dengan kemajuan dunia hari ini.

\section{Sorotan Literatur}

\section{Transformasi Pendidikan Selaras dengan Pembelajaran Abad ke-21 (PAK21)}

Di era globalisasi kini, matematik menjadi bahasa universal dalam membanding kemahiran pelajar di sebuah negara dengan negara yang lain. Ia menjadi kayu ukur dalam menentukan keberkesanan pendidikan di sesebuah negara. Program Penilaian Pelajar Antarabangsa (PISA) dan kajian Trend Pendidikan Matematik dan Sains Antarabangsa (TIMSS) merupakan antara penanda aras antarabangsa yang digunakan dalam mengukur dan membanding keberkesanan pendidikan matematik di beberapa negara. Berdasarkan kerangka kerja PISA 2021, penilaian berfokus kepada mengukur kemahiran pelajar di peringkat sekolah menengah dalam kemahiran penaakulan dan penyelesaian masalah Matematik (Zahid, 2020). Manakala TIMSS pula mengukur kemampuan pelajar gred empat dan gred lapan dalam subjek Matematik dan Sains (Rossalmi, 2016). Justeru itu, keputusan PISA dan TIMSS sangat membantu kementerian pendidikan dalam menentukan sesebuah polisi pendidikan. Ia juga menjadi input utama dalam merangka Pelan Pembangunan Pendidikan Malaysia (PPPM).

Transformasi pendidikan merupakan antara perkara yang ditekankan dalam PPPM (2013-2015). Ia bagi memastikan pelajar dibekalkan dengan pengetahuan dan kemahiran yang diperlukan juga menambah baik kualiti serta penyampaian sistem pendidikan yang ada. Sehubungan dengan itu, Kementerian Pendidikan Malaysia telah melakukan perubahan dalam pendidikan melalui pelaksanaan Kurikulum Standard Sekolah Rendah (KSSR) dan Kurikulum Standard Sekolah Menengah (KSSM) bermula pada tahun 2013. Usaha ini sentiasa ditambah baik sehinggalah bermula PPPM Gelombang 2 (2016-2020) di mana kurikulum disemak semula dan dilaksanakan secara berperingkat bermula pada tahun 2017. Penambahbaikan ini dilaksanakan bagi memastikan pelajar yang dilahirkan oleh sistem 
persekolahan di Malaysia memiliki kemahiran yang selaras dengan pendidikan abad ke-21 dan mampu bersaing di peringkat global.

Satu daripada enam ciri utama yang diperlukan dalam melahirkan pelajar yang mampu bersaing di peringkat global ialah kemahiran berfikir aras tinggi (KBAT) (PPPM 2013-2025). KBAT merujuk kepada keupayaan untuk mengaplikasikan pengetahuan, kemahiran dan nilai dalam membuat penaakulan dan refleksi bagi menyelesaikan masalah, membuat keputusan, berinovasi dan berupaya mencipta sesuatu (KPM, 2014). Menurut Roselizam, Roslan dan Amirah (2020), KBAT adalah keupayaan untuk mengaplikasikan, pengetahuan, kemahiran dan nilai dalam membuat penaakulan dan refleksi bagi menyelesaikan masalah, membuat keputusan, berinovasi dan berupaya mencipta sesuatu. Hal ini berbeza dengan kemahiran berfikir aras rendah yang hanya melibatkan aplikasi rutin, mekanistik dan penggunaan minda yang terhad (Nooriza \& Effandi, 2015). Terdapat empat elemen KBAT yang ditekankan dalam kurikulum Malaysia iaitu mengaplikasikan, menganalisis, menilai dan mencipta (KPM, 2017).

\section{Peranan Buku Teks dalam Pengajaran dan Pembelajaran Matematik}

Dalam konteks pembelajaran matematik, KBAT dilatih melalui penggunaan bahan pengajaran termasuklah buku teks. Marlaine, Stephen dan Bruce (1986) mendefinisikan buku teks sebagai manuskrip teknikal yang disediakan berdasarkan kurikulum pendidikan dalam menyampaikan ilmu yang selari dengan tahap kognitif pelajar, kandungan yang disusun daripada mudah kepada sukar dan membolehkan pelajar untuk membina pengetahuan secara sistematik. Sebagai media pembelajaran utama yang menjadi rujukan guru dan pelajar, buku teks bukan sahaja berperanan sebagai medium penyampaian ilmu bahkan membantu guru dalam membuat keputusan berkaitan strategi, pendekatan, aktiviti dan bahan pengajaran (Yang, Tseng \& Wang, 2017). Tambahan lagi, buku teks merupakan indikator terbaik dalam mengukur kebolehan pelajar dalam mempelajari matematik kerana ia dibuat berdasarkan Dokumen Standard Kurikulum dan Pentaksiran (DSKP) yang menepati sukatan pelajaran dan seragam di semua sekolah.

Harus disedari bahawa penggunaan buku teks bukan hanya satu-satunya bahan kurikulum dan faktor utama yang mempengaruhi pencapaian matematik pelajar. Walau bagaimanapun, oleh kerana buku teks menjadi rujukan penting dalam menentukan prestasi pelajar dalam matematik, beberapa kajian telah membuktikan bahawa analisis buku teks mampu memberi penjelasan berkaitan pengaruh dalam pencapaian pelajar (Cory et al., 2017; Restu \& Tri, 2019).

\section{Aras KognitifSoalan}

Bloom et al. (1956) telah mengklasifikasikan tingkat intelek dalam membantu guru merancang objektif pembelajaran dan pengalaman juga aras soalan peperiksaan berbentuk hierarki yang dikenali sebagai Taksonomi Bloom. Hierarki pengetahuan ini digunakan dalam pembentukan kurikulum pendidikan di pelbagai negara termasuklah Malaysia. Terdapat enam aras kognitif yang ditekankan iaitu pengetahuan, kefahaman, aplikasi, analisis, sintesis dan penilaian (AlKhateeb, 2019). Setiap tingkat aras pengetahuan ini wajib dikuasai oleh pelajar untuk mencapai aras seterusnya.

Kajian pendidikan berkaitan aras kognitif Taksonomi Bloom telah dijalankan oleh beberapa pengkaji antaranya Anderson dan Krathwohl (2001), Krathwohl (2002) dan Clark (2010). Mereka mendapati bahawa kemampuan pelajar dalam mengaplikasikan pengetahuan yang dipelajari adalah bukti kukuh dalam menentukan kefahaman dan penguasaan topik pembelajaran. Justeru itu, setiap aras pengetahuan adalah selari dengan proses kognitif yang terlibat. Semakin tinggi aras kognitif soalan berdasarkan hierarki Taksonomi Bloom, maka murid perlu mengaplikasikan aras pemikiran yang lebih tinggi dalam menyelesaikannya.

Aras kognitif diklasifikasikan bermula dengan aras pengetahuan dan kefahaman yang merupakan aras paling bawah dalam Taksonomi Bloom. Ia menguji murid berkaitan fakta dan konsep yang perlu diingat oleh pelajar, memberi sebab bagi sesuatu idea dan kemampuan memberi penjelasan berkaitan sesuatu fenomena. Aras kedua pula melibatkan kemahiran mengaplikasikan di mana pelajar perlu 
menggunakan pengetahuan sedia ada dalam situasi yang baru. Aras ketiga iaitu aras tertinggi dalam taksonomi Bloom pula melibatkan kemahiran membuat inferens. Pada aras ini, pelajar diuji dalam kemahiran berfikir, menilai dan memberi pandangan serta alasan yang wajar. Kemampuan pelajar untuk membuat perkaitan, membuat pertimbangan dan perbandingan serta menilai sesuatu isu dan permasalahan dikategorikan sebagai Kemahiran Berfikir Aras Tinggi (KBAT).

Selain kurikulum dan peperiksaan awam, klasifikasi aras kognitif yang ditekankan dalam hierarki Taksonomi Bloom juga selari dengan aras soalan yang diaplikasikan dalam ujian TIMSS (Martin et al., 2012). Berdasarkan TIMSS (2015), 35\% soalan yang diuji melibatkan soalan aras pengetahuan dan kefahaman, 35\% soalan aplikasi dan 30\% merupakan soalan pada aras membuat inferens. Justeru itu, penekanan terhadap penguasaan kemahiran berfikir tidak seharusnya tertumpu kepada suatu aras sahaja. Pelajar perlu menguasai pelbagai aras kognitif soalan khususnya pada peringkat yang lebih tinggi iaitu KBAT.

\section{Elemen KBAT dalam Kurikulum Matematik Semakan (2017)}

Bermula tahun 2017, Kurikulum Standard Sekolah Rendah (KSSR) Semakan diperkenalkan dan mula digunakan bagi menggantikan KSSR (2011) sebelumnya. Perubahan ini dilakukan secara berperingkat bermula dengan Tahun 1 pada Tahun 2017 diikuti dengan Tahun 2 pada tahun 2018, Tahun 3 pada tahun 2019 dan yang terkini Tahun 4 pada Tahun 2020. Beberapa perubahan dan penambahbaikan dilakukan antaranya dari segi pelaksanaan proses pengajaran dan pemudahcaraan (PDPc), amalan pentaksiran dan perubahan Dokumen Standard Kurikulum dan Pentaksiran (DSKP) yang menekankan pendekatan berbentuk modular (KSSR, 2017).

Penambahbaikan kurikulum telah membawa perubahan kepada buku teks yang digunakan di sekolah. Bilangan bab dikurangkan namun kandungan dan isi pembelajaran ditambah bagi memperluaskan lagi skop pengetahuan pelajar. Pendekatan berbentuk modular yang diperkenalkan lebih bersifat fleksibel bagi membolehkan guru menggunakan pelbagai strategi pengajaran dan pembelajaran yang lebih bersifat PAK21 seperti pembelajaran masteri, pembelajaran kontekstual, pembelajaran berasaskan projek, pembelajaran berasaskan masalah, simulasi dan inkuiri penemuan.

Walau bagaimanapun, elemen KBAT yang digunakan dalam KSSR Semakan ini masih mengekalkan empat tahap pemikiran seperti dalam KSSR sebelumnya iaitu mengaplikasikan, menganalisis, menilai dan mencipta (KSSR, 2011). Berdasarkan empat elemen ini, murid dibentuk dengan kemahiran Matematik dan dinilai dengan enam tahap penguasaan yang ditunjukkan melalui proses Matematik, iaitu penyelesaian masalah, penaakulan, komunikasi, perkaitan dan perwakilan. Enam tahap penguasaan ini adalah selari dengan hierarki Taksonomi Bloom di mana ia mampu merangsang pemikiran yang lebih berstruktur dan berfokus dalam kalangan pelajar. Justeru itu, soalan, aktiviti dan latihan yang terkandung dalam buku teks KSSR Semakan seharusnya lebih tertumpu dalam menilai enam tahap penguasaan dan menepati aras kognitif yang telah dinyatakan.

\section{Metod Kajian}

Kajian ini merupakan kajian deskriptif dengan pendekatan kualitatif bagi menganalisis secara empirikal dan sistematik berkaitan aras kognitif soalan yang digunakan dalam buku teks Matematik Tahun 4 KSSR Semakan. Buku teks ini diperakui oleh Kementerian Pendidikan Malaysia sebagai rujukan bagi pembelajaran Matematik dalam sistem persekolahan di Malaysia dan ia mula digunakan oleh murid Tahun 4 pada tahun 2020. Pengkaji memilih buku teks Tahun 4 kerana berdasarkan Teori Kognitif Piaget (1972), perkembangan kognitif kanak-kanak berusia 7 hingga 10 tahun berada pada peringkat operasi konkrit. Justeru itu, ia merupakan usia yang sesuai bagi kanak-kanak untuk diperkenalkan dengan kemahiran berfikir aras tinggi. Tambahan lagi, Tahun 4 merupakan murid pertama yang menggunakan KSSR Semakan sejak ia mula diperkenalkan pada tahun 2017.

Kajian ini berfokus kepada analisis dua kriteria; kod aras kognitif dan elemen KBAT. Analisis kriteria aras kognitif soalan dijalankan dengan mengadaptasi Model Kod Analisis Aras Kognitif Soalan oleh 
Noor Rohana (2018) yang menjalankan analisis aras kognitif soalan buku teks Bahasa Melayu Sekolah Menengah. Model ini digunakan bagi menentukan kategori-kategori kompleksiti soalan mengikut pengelasan hierarki pemikiran (Noor Rohana, 2018). Pengelasan dibuat berdasarkan tiga tahap pemikiran iaitu tahap pengetahuan, aplikasi dan penilaian yang mana ia bertepatan dengan perkembangan tahap pemikiran secara logik dan rasional menurut Bloom (1956).

Model Kod Analisis Aras Soalan ini mengelaskan soalan mengikut tiga subkategori atau tiga jenis soalan iaitu soalan interpretasi, soalan aplikasi dan soalan penilaian. Setiap jenis soalan diperincikan lagi menjadi sub-sub kategori yang merujuk kepada pecahan aspek-aspek penyoalan yang lebih kecil, khusus dan jelas di bawah setiap subkategori soalan (Noor Rohana, 2018). Perincian Model Kod Analisis Aras Soalan yang telah diadaptasi dapat dilihat berdasarkan Jadual 1. Adaptasi ini dilakukan dengan merujuk aspek soalan bagi domain pengetahuan, aplikasi dan penilaian berdasarkan Kerangka Matematik TIMSS 2015 (Grønmo et al., 2015). Kerangka Matematik TIMSS 2015 dijadikan rujukan kerana ia menjadi penanda aras antarabangsa dalam menilai kualiti kurikulum pendidikan negara agar selari dengan keperluan di peringkat global.

Jadual 1: Perincian Model Kod Analisis Aras Soalan

\begin{tabular}{llll}
\hline $\begin{array}{l}\text { Kod } \\
\text { Aras }\end{array}$ & Kategori Utama & Sub kategori & Sub-sub kategori \\
\hline I. & Soalan tahap literal & Soalan pengetahuan & Tugasan soalan: \\
& Kriteria soalan: & Fokus soalan: & Mengingat \\
& Soalan dengan sumber & Mengumpul maklumat & Mengecam \\
& jawapan yang jelas & Mengelas/menyusun \\
& diperolehi daripada teks, & & Mengira \\
& maklumat atau gambar rajah. & & Mengukur \\
\hline II. & Soalan tahap inferensi & Soalan aplikasi & Tugasan soalan: \\
& Kriteria soalan: & Fokus soalan: & Menentukan \\
& Soalan dengan sumber & Menggunakan maklumat & Mewakilkan/model \\
& jawapan yang tidak langsung & & Melaksanakan/ \\
& daripada teks, maklumat atau & & menggunakan \\
& gambar rajah. Melibatkan & & \\
& tindakan untuk berfikir dan & & \\
mencari maklumat. & & Tugasan soalan: \\
\hline III. & Soalan tahap penilaian & Soalan penilaian & Menilai \\
& Kriteria soalan: & Fokus soalan: & Menganalisis \\
& Soalan dengan maklumat & Menilai maklumat & Mensintesis \\
& jawapan di luar kandungan & & Membuat konklusi \\
& teks, maklumat atau gambar & & Membuktikan \\
& rajah. Melibatkan tindakan & & \\
berfikir, menilai dan & & \\
membuat pembuktian. & & \\
\hline
\end{tabular}

\section{Kaedah Analisis}

Pengelasan kriteria soalan megikut soalan penerangan dan soalan penilaian dilaksanakan serentak dengan penandaan mengikut jenis Kod Aras Kognitif iaitu Kod Aras I (soalan tahap literal), Kod Aras II (soalan tahap inferensi) dan Kod Aras III (soalan tahap penilaian). Jadual 2 memaparkan contoh soalan Kod Aras I. Jadual 3 pula menunjukkan contoh soalan kod Aras II. Manakala Jadual 4 memaparkan contoh soalan bagi Kod Aras III.

Jadual 2: Contoh soalan Kod Aras I (KA I)

\begin{tabular}{lll}
\hline Soalan: Apakah nilai tempat dan nilai digit bagi 6 dalam nombor 62 307? (KPM 2019, ms. 4) \\
\hline Kriteria soalan & Soalan penilaian & $\begin{array}{l}\text { Dikodkan sebagai soalan penilaian kerana ia } \\
\text { adalah satu aktiviti pengayaan. }\end{array}$
\end{tabular}


Tahap Soalan Literal Dikodkan sebagai soalan tahap literal kerana

Kod Aras Kognitif (KA) I maklumat jawapan diperolehi daripada teks. Dikodkan sebagai KA I kerana ia melibatkan tindakan mengecam dan mengingat fakta.

Jadual 3: Contoh soalan Kod Aras II (KA II)

\begin{tabular}{lll}
\hline $\begin{array}{l}\text { Soalan: Sebanyak } 98070 \text { botol cecair mandian hendak diagihkan sama banyak ke 65 buah } \\
\text { kedai. Berapakah baki botol cecair mandian? (KPM 2019, ms. 42) }\end{array}$ \\
\hline Kriteria soalan & Soalan penerangan & $\begin{array}{l}\text { Dikodkan sebagai soalan penerangan kerana } \\
\text { ia adalah satu aktiviti contoh. } \\
\text { Tahap Soalan }\end{array}$ \\
Inferensi & $\begin{array}{l}\text { Dikodkan sebagai soalan tahap inferensi } \\
\text { kerana sumber jawapan yang tidak langsung } \\
\text { daripada teks. }\end{array}$ \\
Kod Aras Kognitif (KA) & II & $\begin{array}{l}\text { Dikodkan sebagai KAII kerana ia melibatkan } \\
\text { tindakan untuk berfikir dan mencari } \\
\text { maklumat. }\end{array}$ \\
\hline
\end{tabular}

Jadual 4: Contoh soalan Kod Aras III (KA III)

\begin{tabular}{|c|c|c|}
\hline \multicolumn{3}{|c|}{$\begin{array}{l}\text { Soalan: Rishi merancang untuk membeli satu set permainan berharga RM155 dalam tempoh } 3 \\
\text { bulan lagi dengan menabung wang sakunya. } \\
\text { a) Apakah yang perlu Rishi lakukan? } \\
\text { b) Rishi menabung RM3 setiap hari. Adakah matlamat Rishi akan tercapai? (KPM 2019, ms. } \\
\text { 138) }\end{array}$} \\
\hline Kriteria soalan & Soalan penilaian & $\begin{array}{l}\text { Dikodkan sebagai soalan penilaian kerana ia } \\
\text { adalah satu aktiviti pengayaan. }\end{array}$ \\
\hline Tahap Soalan & Penilaian & $\begin{array}{l}\text { Dikodkan sebagai soalan tahap penilaian } \\
\text { kerana maklumat jawapan diluar kandungan } \\
\text { teks. }\end{array}$ \\
\hline Kod Aras Kognitif (KA) & III & $\begin{array}{l}\text { Dikodkan sebagai KA III kerana ia melibatkan } \\
\text { tindakan berfikir dan menilai. }\end{array}$ \\
\hline
\end{tabular}

Prosedur menyemak dan menandakan dilakukan oleh pengkaji terlebih dahulu menggunakan instrumen borang senarai semak. Bagi memastikan kesahan dan kebolehpercayaan data yang telah dikutip, dua orang penilai melaksanakan prosedur menyemak dan menandakan kod-kod bagi soalan matematik secara berasingan. Sebelum prosedur ini dilaksanakan, penilai yang dipilih dilatih menggunakan kod aras soalan berdasarkan skema penandaan bagi kajian ini dan seterusnya menjalani ujian rintis penandaan. Ujian rintis ini bagi memastikan penilai yang dipilih mahir mengelaskan jenis soalan dan menentukan kod aras soalan.

Dapatan data bagi kod soalan yang dilakukan oleh dua penilai ini dibandingkan dengan kod yang telah ditandai oleh pengkaji dengan menggunakan analisis Indeks Cohen Kappa menggunakan program SPSS Version 23. Keputusan analisis menunjukkan bahawa nilai kappa bagi pengkaji dengan Penilai 2 melibatkan analisis ketiga-tiga Kod Aras Kognitif untuk soalan penilaian dan soalan penerangan menunjukkan nilai kappa yang memuaskan $(\mathrm{k}>.70)$ begitu juga dengan pengkaji dengan Penilai 3. Nilai kappa yang ditunjukkan antara .70 hingga .79. Oleh yang demikian, kebolehpercayaan data kajian yang dipungut wujud berdasarkan perbandingan analisis pengekodan ketiga-tiga penilai (Cohen, 1960).

\section{Hasil Kajian}

\section{Analisis Kod Aras Kognitif Soalan}


DOI: https://doi.org/10.47405/mjssh.v6i3.712

Daripada dapatan analisis kriteria soalan, terdapat 325 soalan penerangan dan 596 soalan penilaian. Maka jumlah keseluruhan soalan di dalam buku teks Matematik Tahun 4 KSSR Semakan 2017 ialah sebanyak 921 soalan. Jadual 5 jumlah keseluruhan soalan mengikut Kod Aras Kognitif .

Jadual 5 Jumlah keseluruhan soalan mengikut Kod Aras Kognitif

\begin{tabular}{lllll}
\hline Kod Aras & $\begin{array}{l}\text { Soalan } \\
\text { penerangan }\end{array}$ & $\begin{array}{l}\text { Soalan } \\
\text { penilaian }\end{array}$ & Jumlah & $\begin{array}{l}\text { Peratus } \\
(\boldsymbol{\%})\end{array}$ \\
\hline KA I (soalan tahap literal) & 47 & 117 & 164 & 17.81 \\
\hline KA II (soalan tahap inferensi) & 271 & 395 & 666 & 72.31 \\
\hline KA III (soalan tahap penilaian) & 7 & 84 & 91 & 9.88 \\
\hline
\end{tabular}

Berdasarkan Jadual 5, sebanyak 164 (17.81\%) soalan merupakan soalan tahap literal (KAI). 666 $(71.31 \%)$ soalan merupakan soalan tahap inferensi seterusnya $91(9.88 \%)$ soalan pula merupakan soalan tahap penilaian. Peratus soalan penilaian dan soalan penerangan mengikut Kod Aras Kognitif boleh dilihat dengan lebih jelas pada Rajah 1.

Rajah 1: Peratus soalan penilaian dan soalan penerangan mengikut Kod Aras Kognitif

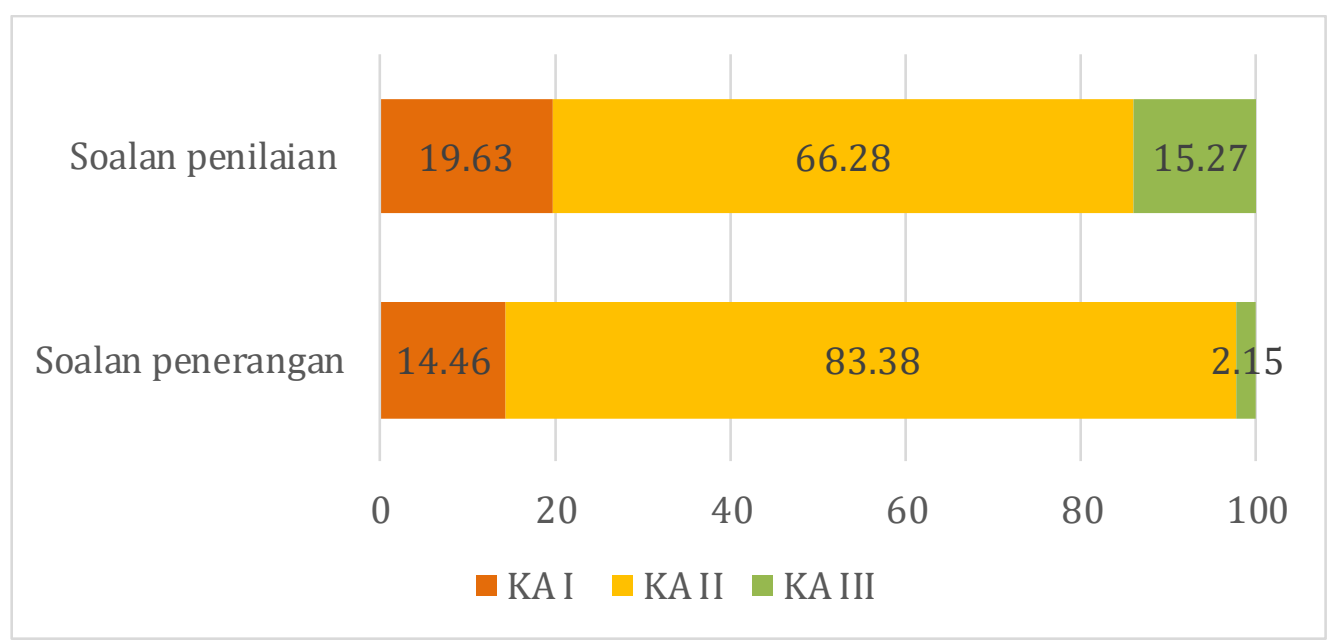

Berdasarkan Rajah 1, peratus soalan tahap inferensi (KAII) menunjukkan peratus yang terbesar bagi kedua-dua jenis soalan iaitu $83.38 \%$ bagi soalan penerangan dan $66.28 \%$ bagi soalan penilaian. Soalan tahap literal (KAI) dan soalan tahap penilaian (KAIII) lebih banyak digunakan dalam soalan penilaian berbanding soalan penerangan.

Rajah 2 Peratus keseluruhan soalan mengikut Kod Aras Kognitif

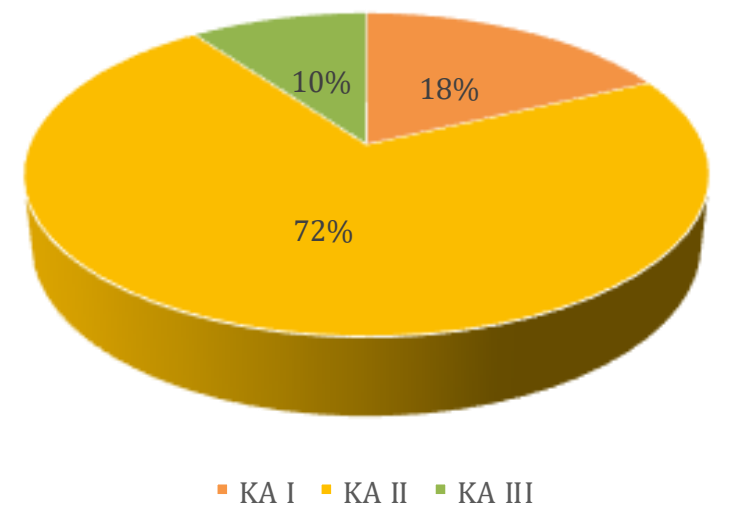


Rajah 2 menunjukkan peratus keseluruhan soalan mengikut Kod Aras Kognitif. Peratus soalan tahap inferensi (KAII) merupakan aras soalan yang terbanyak dengan $72 \%$ diikuti soalan tahap literal (KAI) sebanyak $18 \%$ dan soalan tahap penilaian (KAIII) sebanyak $10 \%$. Hal ini menunjukkan bahawa soalan tahap inferensi (KAII) merupakan aras soalan yang terbanyak digunakan dalam buku teks Matematik Tahun 4 KSSR Semakan 2017.

\section{Analisis Elemen Kemahiran Berfikir Aras Tinggi (KBAT)}

Tiga elemen KBAT yang ditekankan dalam buku teks Matematik Tahun 4 KSSR Semakan ialah pengetahuan, mengaplikasikan dan menilai.

Rajah 3: Peratus keseluruhan soalan mengikut elemen KBAT

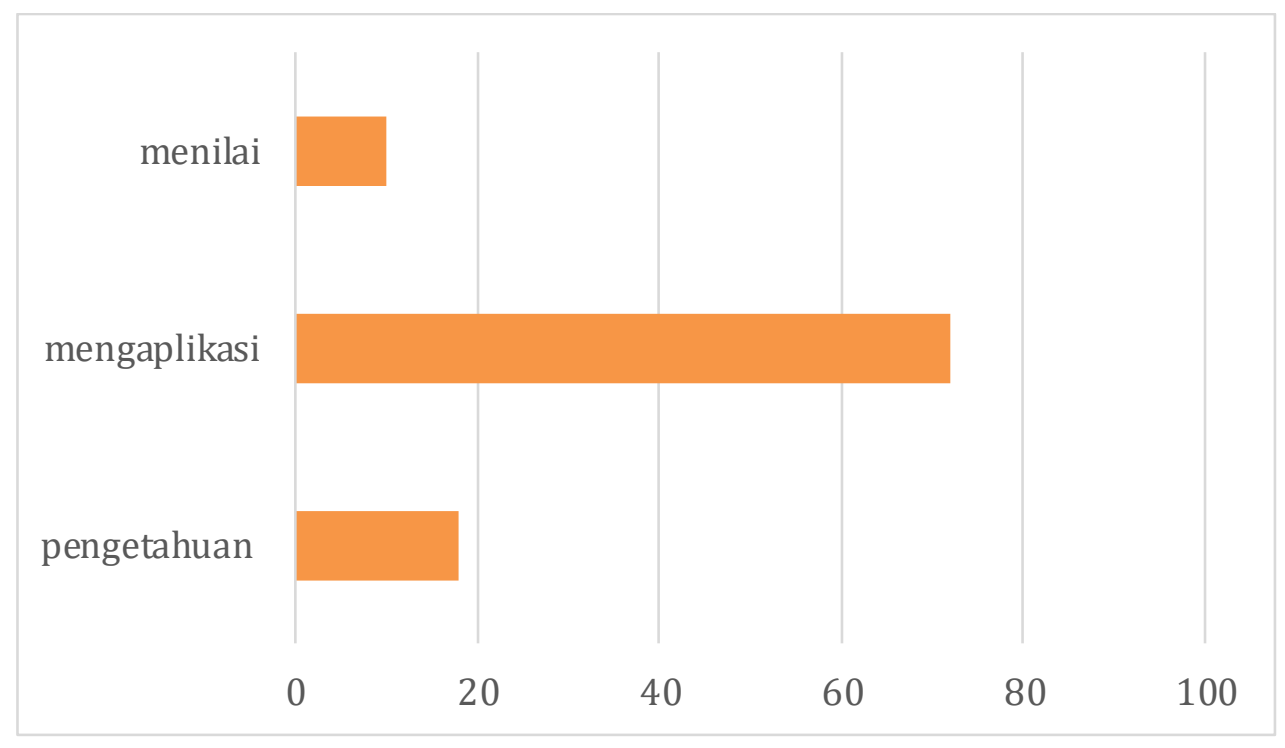

Rajah 3 menunjukkan peratus keseluruhan soalan mengikut elemen KBAT. Peratus ini selari dengan peratus soalan mengikut kod aras kognitif. Peratus soalan tahap mengaplikasikan merupakan aras soalan yang terbanyak dengan $72 \%$ diikuti soalan tahap pengetahuan sebanyak $18 \%$ dan soalan tahap menilai sebanyak $10 \%$. Hal ini menunjukkan bahawa elemen mengaplikasikan merupakan tahap elemen KBAT yang terbanyak digunakan dalam buku teks Matematik Tahun 4 KSSR Semakan 2017.

\section{Perbincangan Kajian}

\section{Aras Kognitifbagi soalan dalam buku teks Matematik KSSR Tahun 4 KSSR Semakan}

Hasil daripada analisis kajian mendapati bahawa bilangan soalan penilaian dalam buku teks Matematik KSSR Semakan Tahun 4 adalah lebih dominan berbanding bilangan soalan penerangan. Hal ini menunjukkan bahawa buku teks yang digunakan lebih berfokus untuk menguji pengetahuan dan menggalakkan murid mengaplikasikan kemahiran Matematik berbanding sekadar memberi penerangan kepada murid. Sememangnya fungsi buku teks haruslah menjadi medium bagi murid untuk mengaplikasikan konsep matematik yang telah mereka pelajari (Yang, Tseng \& Wang, 2017).

Selain itu, jenis soalan dan aktiviti dalam kriteria soalan penilaian juga tidak hanya tertumpu kepada soalan yang menilai pengetahuan konseptual Matematik berbentuk abstrak tetapi turut menggalakkan murid untuk meneroka kemahiran melalui aktiviti-aktiviti berkumpulan berbentuk permainan contohnya aktiviti yang dicadangkan dalam teroka ria. Ia mampu menggalakkan pembelajaran konsep Matematik yang lebih bermakna buat murid apabila mereka mampu bermain sambil belajar (Tersia Yenusi, Jeinne Mumu \& Benidiktus Tanujaya, 2019). 
Walaubagaimanapun, jumlah keseluruhan soalan dalam buku teks Matematik KSSR Semakan 2017 iaitu sebanyak 921 soalan menunjukkan pengurangan dari bilangan jumlah soalan dalam buku teks Matematik KSSR 2011 yang mengandungi 1476 soalan (Kai Joo Tan, Zaleha Ismail \& Mardhiyana Abidin, 2017). Hal ini disebabkan faktor perubahan pendekatan berbentuk modular dalam KSSR 2017 yang menyebabkan bilangan bab dikurangkan. Namun isi pembelajaran telah ditambah bagi memperluaskan lagi skop pengetahuan pelajar. Pendekatan ini cenderung bersifat fleksibel bagi membolehkan guru pengaplikasian pelbagai pengajaran dan pembelajaran yang lebih bersifat PAK21.

Hasil daripada analisis kajian mendapati bahawa bilangan soalan tahap inferensi (Kod Aras II) ialah jenis soalan yang paling banyak diuji dalam buku teks Matematik KSSR Semakan Tahun 4. Ini bermakna kebanyakan soalan melibatkan soalan aplikasi yang memerlukan murid untuk berfikir dan mencari maklumat serta menggunakan kemahiran Matematik yang telah dipelajari. Hal ini selari dengan Teori Piaget (1972) di mana tahap pemikiran murid yang berada dalam lingkungan 7 tahun hingga 11 tahun ialah peringkat operasi konkrit di mana murid sudah mula berupaya untuk melaksanakan perkara di dalam pemikiran mereka secara logik dan operasi.

Kriteria soalan pada tahap inferensi ialah soalan dengan sumber jawapan yang tersirat iaitu tidak dinyatakan dengan jelas menerusi maklumat dari teks atau gambar rajah. Tugasan soalan jenis ini melibatkan arahan operasi pemikiran pelajar yang menjurus ke arah kompleksitinya dan memerlukan murid untuk berfikir merentasi maklumat (Noor Rohana, 2018). Ia menggalakkan murid meneroka pemikiran kreatif dan kritis dengan merujuk dan mengumpul maklumat disamping membuat perkaitan dengan pengalaman dan pengetahuan sedia ada.

Terdapat dua fokus utama soalan pada tahap inferensi yang diaplikasikan dalam buku teks Matematik Tahun 4 KSSR Semakan. Pertama, murid perlu mentafsir maklumat di mana tugasan soalan memerlukan murid memahami kata kunci dan masalah dalam teks dan maklumat. Kedua, soalan yang memerlukan murid menggunakan maklumat dan kemahiran prosedural untuk menjelaskan sesuatu perkara, membuat perbandingan, memberikan sebab dan alasan serta menyelesaikan masalah. Tahap soalan ini tak hanya tertumpu dalam jenis soalan penilaian tetapi juga dalam contoh-contoh dalam soalan penerangan. Pelbagai pendedahan soalan melibatkan permasalahan harian diberikan. Hal ini menunjukkan perubahan kurikulum yang selari dengan tuntutan aras soalan di peringkat TIMSS di mana 35\% soalan melibatkan soalan aplikasi (TIMSS, 2015). Soalan-soalan sebegini mampu meningkatkan tahap kefahaman murid dan menjadikan ilmu yang dipelajari lebih bermakna (Restu \& Tri, 2019).

Seterusnya, soalan tahap literal (Kod Aras I) merupakan soalan kedua terbanyak digunakan dalam buku teks Matematik KSSR Semakan. Soalan pada tahap ini melibatkan soalan dengan maklumat jawapan yang lebih tersurat dan dikategorikan sebagai soalan aras rendah. Penggunaan gambar rajah, jadual dan aplikasi situasi yang lebih mudah tertumpu dalam soalan penilaian di mana murid diuji untuk mengingat fakta dan maklumat yang telah dijelaskan dalam contoh-contoh soalan penerangan. Dalam buku teks KSSR 2011, domain soalan tahap literal merupakan domain yang terbanyak diuji berbanding soalan tahap inferensi dan penilaian (Kai Joo Tan, Zaleha Ismail \& Mardhiyana Abidin, 2017). Hal ini membuktikan bahawa Kurikulum Semakan 2017 sememangnya telah menambah baik kurikulum sebelumnya agar lebih relevan dengan murid hari ini yang lebih terdedah dengan pelbagai maklumat.

Selain itu, soalan tahap penilaian (Kod Aras III) merupakan soalan yang turut diuji dalam kedua-dua jenis soalan penilaian dan soalan penerangan. Namun bilangan soalan pada tahap ini lebih sedikit berbanding soalan tahap inferensi dan soalan tahap literal. Soalan tahap penilaian merujuk kepada soalan aras tinggi dalam kerangka operasional kajian. Ia cenderung lebih mencabar kerana memerlukan murid untuk berfikir merentasi kandungan maklumat dengan mengaplikasikan kemahiran pemikiran kritikal, logik dan rasional (Noor Rohana, 2018). Dalam soalan penilaian buku teks Matematik Tahun 4 KSSR Semakan, soalan ini diuji secara khusus dalam aktiviti maskod dan aktif minda serta soalan-soalan berbentuk penyelesaian masalah berayat dalam aktiviti maju minda dan jana minda. 
Walaupun bilangan soalan tahap penilaian kurang berbanding soalan lain, wujudnya soalan tahap ini menunjukkan murid Tahun 4 telah mendapat pendedahan dengan soalan berunsur KBAT. Tambahan lagi, buku teks Matematik KSSR Semakan juga cenderung memiliki tahap kompleksiti yang pelbagai bersesuaian dengan aras soalan di peringkat TIMSS yang menguji ketiga-tiga tahap soalan (TIMSS, 2016).

\section{Elemen KBAT yang diterapkan dalam buku teks MatematikTahun 4 KSSR Semakan}

Berdasarkan analisis dapatan kajian, elemen KBAT yang paling ditekan dalam buku teks Matematik KSSR Semakan Tahun 4 ialah elemen mengaplikasikan dan menganalisis. Hal ini kerana Soalan Tahap Literal (Kod Aras II) yang merupakan bilangan soalan dominan berfokus kepada dua elemen ini.

Elemen mengaplikasikan merujuk kepada kebolehan murid dalam menggunakan prinsip serta konsep Matematik pada satu masalah dan situasi baru (Restu \& Tri, 2019). Dalam buku teks Matematik KSSR Semakan Tahun 4, elemen ini wujud dalam soalan penilaian berbentuk masalah berayat yang melibatkan situasi harian berbanding soalan penerangan. Hal ini secara tidak langsung melatih murid dalam menguasai kemahiran Matematik dengan lebih efektif kerana murid dapat melihat bagaimana Matematik diaplikasikan dalam kehidupan.

Selain itu, soalan-soalan tahap mengaplikasikan yang diuji kepada murid tidak semuanya melibatkan pengiraan. Terdapat sebahagian soalan yang memerlukan murid untuk menilai situasi, menentukan langkah pengiraan yang tepat juga menguji murid berkaitan kefahaman konsep dengan memberikan sebab dan justifikasi yang relevan. Soalan-soalan seperti ini melibatkan pencarian sumber jawapan yang tidak diperoleh langsung daripada teks, maklumat mahupun gambar rajah. Ia memerlukan murid untuk berfikir dengan menggunakan kemahiran kognitif mereka dalam membuat penaakulan berdasarkan formula logik dan data yang benar.

Bagi elemen menganalisis pula, ia melibatkan kebolehan murid dalam memisahkan sesuatu idea dan maklumat kepada elemen-elemen sehingga suatu bentuk pertalian antara elemen tersebut dapat dilihat dengan jelas (Pratama \& Retnawati, 2018). Hal ini dapat dilihat dalam soalan pada Bab 2 yang melibatkan gabungan kemahiran pecahan, perpuluhan dan peratus. Soalan-soalan yang diuji melibatkan ketiga-tiga kemahiran secara berperingkat membolehkan murid membuat perkaitan dan generalisasi bahawa ketiga-tiga kemahiran adalah saling berhubung. Tambahan pula, kebanyakan soalan menggalakkan murid untuk membuat perbandingan, mengenal pasti, membuktikan, menjelaskan dengan contoh dan membincangkan. Walaupun kemahiran kognitif ini berada pada Kod Aras II dalam Model Kod Aras Soalan yang digunakan, ia dianggap aras tinggi bagi murid Tahun 4 yang masih berada pada peringkat pemikiran operasi konkrit. Justeru itu, buku teks Matematik KSSR Semakan Tahun 4 sememangnya menerapkan elemen KBAT yang menepati aras keperluan murid dalam soalan-soalan yang diuji. Kedua-dua elemen KBAT yang dinyatakan diterapkan dalam bentuk soalan yang melibatkan penyelesaian masalah, penaakulan, komunikasi, perkaitan dan perwakilan. Hal ini selari dengan hierarki Taksonomi Bloom dan mampu merangsang pemikiran yang lebih berstruktur dan berfokus dalam kalangan pelajar (KPM, 2014).

Berdasarkan carta piramid KBAT yang dikeluarkan oleh Bahagian Pembangunan Kurikulum (2014), setiap elemen KBAT terbahagi kepada tiga peringkat utama. Peringkat pertama ialah kemahiran berfikir aras rendah melibatkan elemen mengingat dan memahami. Seterusnya peringkat kemahiran berfikir aras sederhana melibatkan elemen mengaplikasikan dan menganalisis. Manakala peringkat tertinggi iaitu KBAT melibatkan elemen menilai dan mencipta. Oleh kerana dapatan analisis soalan bagi bilangan soalan lebih dominan kepada elemen mengaplikasikan dan menganalisis, maka dapat disimpulkan bahawa soalan-soalan buku teks Matematik Tahun 4 KSSR Semakan berada pada aras kemahiran berfikir aras sederhana. 


\section{Kesimpulan}

Hasil daripada perbincangan, dapat disimpulkan bahawa buku teks Matematik KSSR Semakan Tahun 4 memiliki aras kognitif soalan yang menepati keperluan dan kemampuan murid Tahun 4. Dengan bilangan soalan yang dominan pada Tahap Inferensi, buku teks Matematik Tahun 4 berada pada aras kemahiran berfikir aras sederhana berdasarkan carta piramid KBAT (BPK, 2014). Selain itu, soalan yang diuji dalam buku teks cenderung berfokus kepada soalan yang menilai kemahiran Matematik murid dan bukan sekadar memberikan penerangan berkaitan konsep serta prosedural. Hal ini selari dengan PAK21 yang ditekankan oleh KPM yang menuntut pembelajaran lebih berfokus kepada murid (KPM, 2020).

Seterusnya, elemen KBAT dalam buku teks Matematik KSSR Semakan Tahun 4 lebih berfokus kepada mengaplikasi dan menganalisis. Kedua-dua kemahiran merupakan kemahiran yang tinggi bagi peringkat pemikiran murid Tahun 4 dan ianya bersesuaian dengan keperluan serta kemampuan kognitif mereka. Kedua-dua elemen ini juga merupakan dua elemen yang ditekankan dalam Dokumen Standard Kurikulum dan Pentaksiran Matematik (DSKP, 2017) yang mana empat tahap pemikiran yang menjadi fokus bagi kemenjadian murid ialah mengaplikasikan, menganalisis, menilai dan mencipta. Oleh itu, buku teks Matematik KSSR Semakan Tahun 4 menerapkan aras soalan kognitif yang bersesuaian dengan KBAT.

Tambahan lagi, soalan-soalan dalam buku teks Matematik Tahun 4 juga memiliki tahap soalan yang menepati aras soalan di peringkat TIMSS. Tiga tahap soalan yang diuji di peringkat TIMSS melibatkan pengetahuan dan kefahaman, aplikasi serta membuat inferens. Pendedahan murid seawal Tahun 4 kepada kompleksiti soalan-soalan ini mampu membiasakan mereka dengan soalan-soalan yang sukar dan lebih mencabar. Ia secara langsung mempu membentuk efikasi kendiri murid yang melibatkan motivasi berdasarkan kepercayaan diri sendiri dalam menjawab soalan Matematik.

Implikasi dari kajian ini, pihak KPM wajar melihat kajian ini sebagai suatu kajian yang signifikan kerana ia berkait rapat dalam pembentukan kemahiran Matematik murid sebagai persediaan kepada ujian TIMSS pada tahun 2023. Dapatan kajian menunjukkan bahawa penambahbaikan KSSR Semakan 2017 sememangnya bersesuaian dan menepati keperluan murid semasa. Namun begitu, pihak KPM perlu sentiasa cakna terhadap perubahan budaya pendidikan masa kini yang lebih menjurus kepada teknologi maklumat dan ICT. Oleh itu, KPM boleh menerapkan lebih banyak aplikasi teknologi dalam soalan-soalan Matematik contohnya soalan penerangan menggunakan teknologi scanner code atau Argumented Reality (AI). Hal ini mampu menarik minat murid terhadap penggunaan buku teks lebih menarik dan menjadikan pembelajaran murid lebih menyeronokkan. Dapatan kajian Blanche, Gary dan Jennifer (2017) telah membuktikan bahawa murid yang menggunakan buku teks bersifat interaktif memiliki motivasi yang tinggi dan mampu meningkatkan tahap perhatian mereka terhadap topik pembelajaran.

Di samping itu, kajian analisis aras soalan buku teks Matematik KSSR Semakan ini seharusnya mampu memberi idea kepada guru matematik khususnya Tahun 4 bagi memanfaatkan sepenuhnya buku teks Matematik dalam pengajaran dan pembelajaran murid. Sememangnya kemahiran KBAT boleh diterapkan dalam penyoalan secara lisan di dalam kelas, namun penggunaan buku teks mampu membantu guru dalam menentukan bentuk soalan yang lebih bersesuaian melibatkan penyelesaian masalah dan prosedural yang lebih terancang. Selain itu, buku teks juga harus menjadi bahan rujukan utama buat guru dalam merancang dan menentukan bahan bantu serta aktiviti pembelajaran yang sesuai buat murid. Ia tidak seharusnya diabaikan agar kemenjadian murid dalam aspek penerapan KBAT mampu dicapai selari dengan matlamat kurikulum.

Semoga kajian tinjauan ini mampu menyampaikan maklumat kepada masyarakat berkaitan matlamat kurikulum pendidikan di Malaysia yang berfokus untuk melahirkan murid yang berfikiran aras tinggi. Hal ini demikian kerana kemajuan dan pemodenan yang kian rancak pada hari ini menuntut murid yang mampu bersaing di peringkat global. Oleh itu, analisis berkaitan aras kognitif soalan harus ditekankan agar kualiti buku teks yang digunakan di sekolah dapat ditingkatkan bersesuaian dengan keperluan pendidikan Abad ke-21. 


\section{Rujukan}

Anderson, L., Krathwohl, D. (2001). A taxonomy for learning, teaching, and assessing: A revision of Bloom's taxonomy of educational objectives. New York: Longman.

Alkhateeb, M. A. (2019). Assessing Eighth-Grade Mathematics Teachers and Textbook in Embodying Thinking Levels. International Journal of Instruction, 12(1), 371-388. Bloom, B., Engelhart, M., Furst, E., Hill, W., \& Krathwohl, D. (1956). Taxonomy of educational objectives: The classification of educational goals. Handbook I: Cognitive domain. New York, Toronto: Longmans Green.

Blanche W. O'Bannon, Gary J. Skolits \& Jennifer K. Lubke. (2017) The Influence of Digital Interactive Textbook Instruction on Student Learning Preferences, Outcomes, and Motivation, Journal of Research on Technology in Education, 49:3-4, 103116, DOI: 10.1080/15391523.2017.1303798

Cohen. J. (1960). A coeffisient for agreement for nominal scales. Educational and Psychological Measurement., 37-46

Clark, D. (2010). Bloom's taxonomy of learning domains: The three types of learning. In: W.A. Edmonds (Ed.), Big dog \& little dog's performance juxtaposition. Retrieved [22/4/2017] from http://www.nwlink.com/ donclark/hrd/bloom.html

Cory Koedel, Diyi Li, Morgan S. Polikoff, Tenice Hardaway, Stephani L Wrabel. (2017). Mathematics Curriculum Effects on Students Achievement in California. SAGE Journal. DOI: https://doi.org/10.1177/2332858417690511

Der-Ching Yang, Yi-Kuan Tseng, Tzu-Ling Wang. (2017). A Comparison of Geometry Problems in Middle- Grade Mathematics Textbooks from Taiwan, Singapore, Finland, and the United States. EURASIA Journal of Mathematics Science and Technology Education, 13(7):2841-2857

G S Pratama, H Retnawati. (2018). Urgency of Higher Order Thinking Skills (HOTS) Content Analysis in Mathematics Textbook. Journal of Physics, 109-012147. DOI:10.1088/17426596/1097/1/012147

Grønmo, L. S., Lindquist, M. Arora, A., dan Mullis, I. V. (2015). TIMSS 2015 Mathematics Framework. TIMSS, 11-28.

Kai Joo Tan, Zaleha Ismail, Mardhiyana Abidin. (2017). A Comparative Analysis on Cognitive Domain for the Malaysian Primary Four Textbook Series. EURASIA Journal of Mathematics, Science and Technology Education. 14(4):1273-1286 DOI: 10.29333/ejmste/82625

Kementerian Pendidikan Malaysia. (2016). Laporan TIMMS 2015. Kuala Lumpur.

Krathwohl, D. (2002). A revision of Bloom's taxonomy: An overview. Theory into Practice, 41(4), 212-218. doi: 10.1207/s15430421tip4104_2

Kementerian Pendidikan Malaysia. (2017). Pelän Pembangunan Pendidikan Malaysia 2013-2025. Kuala Lumpur.

Martin, M., Mullis, I., Foy, P., Stanco, G. (2012). TIMSS 2011 International results in science. Chestnut Hill, MA: TIMSS \& PIRLS International Study Center, Boston College.

Malaysia, K. P. (2011). Kurikulum Standard Sekolah Rendah.

Malaysia, K. P. (2017). Kurikulum Standard Sekolah Rendah.

Malaysia, K. P. (2016). Laporan TIMSS 2015.

Malaysia, K. P. (2020). Modul Pembelajaran Abad ke-21.

Malaysia, K. P. (2014). Kemahiran Berfikir Aras Tinggi. Kuala Lumpur.

Malaysia, K. P. (2019). Matematik Tahun 4 KSSR Semakan 2017.

Malaysia, K. P. (2020). Pentaksiran Kompetensi dan Literasi 2020

.Nooriza kassim, Effandi Zakaria. (2015). Integrasi Kemahiran Berfikir Aras Tinggi Dalam Pengajaran dan Pembelajaran Matematik: Analisis Keperluan Guru. Jurnal Pendidikan Matematik 3(1), 1-12.

Noor Rohana Mansor. (2018). Aras Kognitif Soalan: Menjana Kualiti Soalan. Penerbit UMT, Universiti Malaysia Terengganu. Kuala Nerus, Terengganu.

Piaget, J. (1972). Intellectual Evolution from Adolescence to Adulthood. Human Development, 15 (1), 1-12. doi:10.1159/000271225

Restu Lusiana, Tri Andari. (2019). Developing Algebra Textbook Based on Problem Solving to Improve Students Learning Achievement. Al-Jabar: Jurnal Pendidikan Matematika, 10(2), 293306. 
Roselizam Daud, Roslan AB. Rahman, Amirah Wahidah Adnan. (2020). Keberkesanan Peta Pemikiran I-Think dalam Meningkatkan Kemahiran Berfikir Aras Tinggi (KBAT). International Social Science and Humanities Journal. 3(1), 2637-0271

Rossalmi Mohd. Nawi. (2016). Penguasaan domain kognitif aras tinggi dalam Matematik TIMSS murid tahun empat dan korelasinya dengan perlakuan metakognitif. EDUCATUM Journal of Science, Mathematics and Technology (EJSMT).

Sabah, S. A., Fayez, M., Alshamrani, S. M., Mansour, N. (2014). Continuing Professional Development (Cpd) Provision for Science and Mathematics Teachers in Saudi Arabia: Perceptions and Experiences of Cpd Providers. Journal of Baltic Science Education, 13(1).

Tersia Yenusi, Jeinne Mumu, Benidiktus Tanujaya. (2019). Analisis soal latihan pada buku paket matematika SMA yang bersesuaian dengan Higher Order Thinking Skills. Journal of Honai Math. Vol. 2, No. 1, pp. $53-64$.

Marlaine E. Lockheed, Stephen C. Vail, Bruce Fuller. (1986). How Textbooks Affect Achievement in Developing Countries: Evidence From Thailand. SAGE Journal, 8(4); 379-392.

Zahid, M. Z (2020). Telaah Kerangka Kerja PISA 2021: Era Integrasi Computational Thinking dalam Bidang Matematik. PRISMA. Prosiding Seminar Nasional Matematika 3, 706- 713 